\title{
CESPUC
}

\section{DISCURSOS TEXTUAIS E GÊNEROS HÍBRIDOS: DESAFIOS PARA O REVISOR DE TEXTOS}

\author{
Eliene Vieira de Santana*
}

\begin{abstract}
Resumo
O presente trabalho faz uma reflexão sobre a importância da teoria de Gêneros Discursivos no trabalho do Revisor de Textos para o desempenho efetivo de suas funções. A pesquisa terá caráter qualitativo, com revisão da literatura baseada, principalmente, nas obras de Mikail Bakhtin (1997), Antonio Luiz Fiorin (2008), Luiz Antônio Marcuschi (2007) e Adriana S. Pagano (2001) em relação a Gêneros do Discurso e Gêneros híbridos. Para alicerçar a discussão sobre a influência dessa teoria no desempenho do trabalho do Revisor de Textos nos basearemos nas obras de Denise Silva Macedo (2013), Harisson Rocha (2012) e Costa, Rodrigues e Pena (2011). Para embasar a análise textual, utilizaremos, além dos autores já citados, os conceitos apresentados por Josemar dos Santos (2010). Ressaltaremos a importância do conhecimento da Teoria dos Gêneros e do fenômeno da hibridização para o profissional de revisão de textos na realização de seu trabalho cotidiano. Aplicando a teoria à prática, faremos a análise de um texto jornalístico institucional publicado no DOM (Diário Oficial do Município) de Belo Horizonte sobre o aniversário da cidade e de uma publicação do Informativo do Sindicato dos Trabalhadores em Educação da Rede Municipal de Belo Horizonte - SindRede - sobre o mesmo tema. Abordaremos, especialmente, o caráter híbrido do gênero reportagem, que se confunde com o gênero publicitário, no primeiro suporte, e os efeitos da paródia como crítica no segundo suporte. A partir do corpus analisado, buscamos confirmar a teoria de que o fenômeno do hibridismo se realiza não na estrutura textual, mas no âmbito da discursividade.
\end{abstract}

Palavras-chave: Gênero textual. Hibridismo. Revisão de textos.

\section{DISCURSOS TEXTUALES Y GÉNEROS HIIBRIDOS: DESAFÍOS PARA EL REVISOR DE TEXTOS}

El presente trabajo hace una reflexión sobre la importancia de la teoría de Géneros Discursivos en el trabajo del Revisor de Textos para el desempeño efectivo de sus funciones. La investigación tendrá carácter cualitativo, con revisión de la literatura basada principalmente en las obras de Mikail Bakhtin (1997), Antonio Luiz Fiorin (2008), Luiz Antônio Marcuschi (2007) y Adriana S. Pagano (2001) en relación a los Géneros del Discurso Y los géneros híbridos. Para fundamentar la discusión sobre la influencia de esta teoría en el desempeño del trabajo del Revisor de Textos nos basaremos en las obras de Denise Silva Macedo (2013), Harisson Rocha (2012) y Costa, Rodrigues y Pena (2011). Para basar el análisis textual, utilizaremos, además de los autores ya citados, los conceptos presentados por Josemar dos Santos (2010). Resaltaremos la importancia del conocimiento de la Teoría de los géneros y del fenómeno de la hibridación para el profesional de revisión de textos en la realización de su trabajo cotidiano. Para finalizar, aplicando la teoría a la práctica, haremos un análisis de texto periodístico institucional publicado en el DOM (Diario Oficial del Municipio) de Belo Horizonte sobre el cumpleaños de la ciudad y de una publicación del Informativo del Sindicato de los Trabajadores en Educación de la Red Municipal de Belo - Horizonte - SindRed - sobre el mismo tema. En particular, abordamos el carácter híbrido del género noticia, en ese soporte, que se confunde con el género publicitario y los efectos de la parodia como crítica. A partir del corpus analizado, buscamos confirmar la teoría de que el fenómeno del hibridismo se realiza no en la estructura textual, sino en el ambito de la discursividad.

Palabras clave: Género textual. Hibridismo. Revisión de textos

Recebido em: 28/05/2017

Aceito em: 19/09/2017

*Formada em Letras pela UFMG. Especilista em revisão de Textos e Gestão de Projetos Culturais pela PUC Minas. 


\section{Considerações iniciais}

A teoria de gêneros textuais desenvolvida por Bakhtin e o fenômeno da hibridização, em especial nos textos de jornais institucionais, despertou nosso interesse em pesquisar a importância desses temas para o profissional de revisão de textos, uma vez que revestir publicidade com a credibilidade própria da notícia requer não só talento e criatividade, mas também conhecimentos acerca do funcionamento da língua. Nesse contexto, o papel do revisor de texto se torna bastante relevante, pois caberá a ele reconhecer os diversos gêneros textuais, dominar os recursos argumentativos inerentes a cada modalidade discursiva, adptem a linguagem ao suporte e ao público leitor, observar e sugerir formas de adequar o texto aos seus objetivos. Para alicerçar nossa discussão, inicialmente falaremos sobre a teoria dos gêneros e do fenômeno da hibridização na construção da comunicação. Em seguida, focaremos na ocorrência do texto híbrido em jornais institucionais e teceremos algumas considerações sobre a importância e a necessidade de formação do revisor de textos para o desempenho de seu trabalho. Finalizaremos com a análise do corpus, aplicando as teorias abordadas na prática da revisão.

\section{Os gêneros do discurso}

Vários são os estudos realizados em torno da noção de Gêneros Discursivos, elaborada por Bakhtin no livro Estética da Criação Verbal. Tentaremos, resumidamente, dar a conhecer alguns aspectos importantes sobre esse tema, que irão, mais adiante, alicerçar nosso trabalho de análise textual.

Entende-se por gênero discursivo as diversas formas de enunciados elaborados em consonância com as necessidades comunicacionais das diversas esferas sociais, sendo eles que possibilitam a interação sócio-comunicacional entre os indivíduos.

Bakhtin, ao estudar os gêneros, não se ocupou em relacioná-los, uma vez que sabia serem eles infinitos, pois cada grupo social constituído cria gêneros que se adéquem às suas necessidades comunicativas. Inerentes, portanto, às relações humanas, os gêneros são, em sua essência, instáveis. Aparecem, desaparecem ou se modificam atendendo às demandas do grupo que os criou. Segundo Bakhtin (1997), "as diversas formas de se dirigir ao destinatário é que determinam a diversidade de gêneros do discurso", (BAKHTIN, 1997, p.325) o que resulta em uma gama incontável de formas de comunicação e, portanto, de gêneros. Ainda segundo o autor, "cada esfera (da comunicação humana) conhece seus gêneros, apropriados às suas especificidades, aos quais correspondem determinados estilos.” (BAKHTIN, 1997, p. 284)

Recentemente, podemos observar o movimento de criação de diversos gêneros a partir do advento da informatização. E-mails, chats, blogs são alguns, que podemos citar. Pode-se observar também, historicamente, que alguns gêneros sofreram adaptações para continuarem socialmente úteis. É o caso, por exemplo, da notícia, que teve, ao longo do tempo, alterações significativas em sua estrutura textual. 


\section{CESPUC \\ 1 O SEMESTRE DE $2017-$ N. 30}

Apesar dessa instabilidade constatada em relação à permanência dos enunciados nas relações sócio-comunicativas, podemos perceber, paradoxalmente, que, em relação à estruturação, cada gênero tem um caráter estável. É essa estabilidade que nos permite identificar ou distinguir um gênero do outro no universo da comunicação.

Produto social, o gênero discursivo é instrumento fundamental no estabelecimento das relações humanas. Para transitar em determinada esfera social, o indivíduo precisa dominar os gêneros do discurso que a permeiam e, para isso, faz-se necessário à sua vivência no meio que o originou ou que o utiliza, pois, as formas comunicativas do processo de interação não estão disponíveis em manuais, elas se dão na interação entre os indivíduos.

É importante também ressaltar que durante o processo de comunicação, os interlocutores são ativos e que, como nos afirma Bakhtin (1997), "o que ele (o locutor) espera não é uma compreensão passiva, [...] espera é uma resposta, uma concordância, uma adesão, uma objeção, uma execução, etc" (BAKHTIN, 1997, p.291), vinda de seu interlocutor, pois, completa, "cada enunciado é um elo da cadeia muito complexa de outros enunciados". O que melhor ilustra, portanto, o processo de comunicação como interação entre os interlocutores é o diálogo, no qual os turnos de fala ficam mais evidentes.

A partir do processo de comunicação, Bakhtin (1997) esclarece a diferença entre unidades do discurso e gramaticalização. No processo de comunicação, os enunciados são delimitados pela alternância das falas entre os sujeitos e formam uma unidade real de comunicação repleta de significados à espera de um posicionamento do interlocutor, estabelecendo uma relação dialógica. Por sua vez, a unidade gramatical, a oração, pertence a um único indivíduo e se encerra em si mesma, não espera nem determina uma resposta. É essencialmente de natureza gramatical. Dessa forma, conclui o autor que, "as pessoas não trocam orações, assim como não trocam palavras (numa acepção rigorosamente linguística), ou combinações de palavras, trocam enunciados constituídos com a ajuda de unidades da língua [...]” (BAKHTIN, 1997, p.297).

Para ele, assimilamos os gêneros do discurso de forma bastante semelhante à aquisição da fala, ou seja, tanto um quanto o outro se dá no ambiente sócio-comunicativo. Ambos são aprendidos e apreendidos nas relações sociais. Salienta ainda que tanto as formas da língua quanto os gêneros discursivos são assimilados pelos falantes conjuntamente e que nesse processo mantêm uma estreita correlação. "Os gêneros do discurso organizam nossa fala da mesma maneira que a organizam as formas gramaticais (sintáticas).” (BAKHTIN, 1997, p. 302)

Embora não tenha catalogado os diversos gêneros discursivos, dada a infinidade destes, Bakhtin os dividiu em dois grupos, classificando-os em gêneros primários e gêneros secundários. Pertencem ao gênero primário os que fazem parte da comunicação cotidiana e que, em sua maioria, são próprios da oralidade. Ao grupo dos gêneros secundários, pertencem as formas mais elaboradas de comunicação que têm maior representatividade na forma escrita padronizada. Dentre os gêneros secundários, o autor destaca os gêneros literários como sendo os mais complexos, uma vez que se apropriam de diversos gêneros secundários para compor-se: diários íntimos, cartas, reprodução de diálogos, etc. Alerta também para a possibilidade desses gêneros se mesclarem em determinadas situações: uma carta de cunho pessoal pode ser usada como peça integrante de um processo judicial, da mesma forma, um diálogo entre amigos pode adquirir um cunho filosófico. 


\section{CESPUC \\ 1 O SEMESTRE DE $2017-$ N. 30}

Constitui-se, assim, o fenômeno da hibridização, sobre o qual, trataremos a seguir.

\section{Hibridismo textual}

Antes de abordarmos a teoria sobre o fenômeno do hibridismo, faremos um breve histórico sobre a origem e os significados desse termo.

Segundo Azevedo Filho (2008), a palavra hibridismo se originou de estudos da biologia e se aplicava a fenômenos envolvendo a fauna e a flora em relação à impossibilidade de reprodução dessas espécies. Esse fato recebeu a pecha de negativismo, uma vez que um exemplar que não se reproduz não é interessante do ponto de vista da perpetuação da espécie. Posteriormente, o termo foi usado como sinônimo de miscigenação, mantendo-se a ideia pejorativa. A origem do termo mulato-mulata, que vem de mula (animal hibrido), nos dá a extensão que esse fenômeno alcançou. Essa noção de mistura se manteve quando o termo passou a ser aplicado aos gêneros textuais. No entanto, o fenômeno passa a ser visto como algo positivo, pois amplia as possibilidades comunicativas abrindo os horizontes da discursividade. Bakhtin (1997) faz referência a mobilidade e flexibilidade dos gêneros textuais para atender às mudanças sociais, possibilitando o surgimento de gêneros híbridos como forma de atender às demandas sóciodiscursivas. É importante lembrar ainda que os gêneros sofrem influência do tempo e do espaço em que são produzidos e que se moldam para atender às diferentes demandas que cada um desses fatores exige. Marcuschi (2007) alerta para o fato de que "os gêneros não são instrumentos estanques e enrijecedores da ação criativa [...] mas, caracterizam-se como eventos textuais altamente maleáveis, dinâmicos e plásticos” (MARCUSCHI, 2007, p.19) o que significa dizer que os gêneros se ajustam às condições de comunicação e que, para isso, podem se modificar ou se mesclar com outros gêneros preexistentes dando origem a gêneros híbridos.

Para Pagano (2001), a "transformação ou hibridização é inerente às formações genéricas" (PAGANO, 2001, p.87), fenômeno que vem, cada vez mais, sendo objeto de estudos e pesquisas acadêmicas. Para ela, um texto sempre nos remete a um gênero e esse texto servindo de modelo sofrerá as alterações devidas para atender a novas demandas discursivas. Dessa forma:

O hibridismo parece surgir, assim, da práxis ou da produção textual, que, se bem participa de um gênero específico ou se vincula a ele, está sempre ativando outros gêneros. Embora diferenciados no início, esses outros gêneros vão aos poucos incorporando-se e misturando-se com o gênero predominante em primeira instância. (PAGANO, 2001, p.88)

Marcuschi (2007) nos alerta para o fato de que "a tecnologia favorece o surgimento de formas inovadoras, mas não absolutamente novas. " (MARCUSCHI, 2007, p. 20). Um exemplo bastante comum e contemporâneo de hibridismo textual são os $e$-mails que carregam características da carta pessoal, do telefonema que, por sua vez, tem sua origem na conversação. Porém, tanto o e-mail quanto o telefonema mantêm uma estrutura própria caracterizada pelas condições de produção e pelo uso que se faz deles. Acrescenta que os gêneros, que emergiram com as novas tecnologias, trazem uma carga de hibridismo que une oralidade e escrita além de 
integrarem em semioses os signos verbais e não verbais e a sonoridade e que "como certos gêneros já têm um determinado uso e funcionalidade, seu investimento em outro quadro comunicativo e funcional permite enfatizar com mais vigor os novos objetivos". (MARCUSCHI, 2007, p. 21).

Dentro desse processo de produção e adequação dos gêneros às necessidades sóciodiscursivas está a paródia. Nela deparamos com gêneros sendo utilizados para compor outro gênero ou desempenhando funções diferentes daquelas que lhe são inerentes. Marcuschi (2007) denomina de intertextualidade intergêneros "a mescla de funções e formas de gêneros diversos num dado gênero" (MARCUSHI, 2007, P. 31) e cita, como exemplo, um artigo de opinião escrito no formato de poema.

Pagano (2001) lembra-nos que "há outros processos de hibridização discursiva que operam de forma menos explícita e com propósitos outros além do humor e da ironia (comuns na paródia) [...] a intertextualidade e a interdiscursividade” (PAGANO, 2001, p.93). A intertextualidade, processo bastante conhecido e amplamente discutido, especialmente na literatura, é reconhecida como a presença ou citação de um ou vários textos no interior de outro. Já a interdiscursividade diz respeito à constituição do texto, à interdependência de tipos textuais. É através dela que percebemos a mudança de gênero em um determinado texto para adequar-se à demanda discursiva. Essa adequação se faz necessária a partir de fatores como a democratização e suas implicações nas relações sociais, a tecnologização e suas influências nas formas de comunicação, bem como as alterações sócio-econômicas relativas à produção e ao consumo de bens em uma comunidade. Para a autora, "juntamente com os gêneros, mudam os sujeitos que interagem com eles e através deles” (PAGANO, 2001, p. 94). Essa circularidade também foi observada por Bakhtin (1997) quando nos afirma que os gêneros mudam a sociedade e ao mesmo tempo são modificados por ela. Dessa forma, sujeito e gênero agem um sobre o outro numa relação dialética de interdependência.

Na sociedade contemporânea, o dinamismo no processo de mudanças sociais e culturais descortina a fragilidade das estruturas dos gêneros textuais e o fortalecimento do fenômeno da hibridização como resposta às necessidades comunicacionais como se pode observar, por exemplo, em notícias de jornais institucionais onde a divulgação dos feitos e empreendimentos da empresa ou da entidade pública requer um trabalho minucioso do jornalista, para que, ao informar, o faça de forma a agregar valor à instituição e ou ao serviço por ela prestado.

\section{1 Jornalismo Institucional - gênero híbrido}

Para Santos (2010), o jornalismo institucional, assim como o jornalismo informativo ou tradicional, se baseia em fatos, porém não apresenta visão crítica dos conteúdos veiculados. Importante esclarecer que não se trata aqui de emitir opiniões, uma vez que um dos pressupostos apregoados pelo texto jornalístico é a imparcialidade, tema bastante polêmico e que não trataremos aqui devido ao pouco espaço e ao objetivo desse artigo. $\mathrm{O}$ autor ainda nos informa que: 


\section{CESPUC

a diferença entre produzir notícias para jornais institucionais, ou para jornais informativos está no fato de a publicação institucional se preocupar com as necessidades de uma determinada organização, enquanto o jornalismo informativo se volta às necessidades humanas mais amplas, universais. (SANTOS, 2010, p. 33)

É essa preocupação com as necessidades da instituição, a qual o profissional representa, que norteia o trabalho jornalístico dando o tom do discurso argumentativo.

Para chamar a atenção do leitor e atender às demandas do cliente, o jornalista utiliza-se de mecanismos diversos, entre eles, a intertextualidade genérica. Portanto, a leitura do jornal institucional demanda do leitor habilidade para perceber a mescla de gêneros de naturezas distintas na composição do texto, exigindo o despertar de conhecimentos prévios acerca dos gêneros textuais empregados.

Santos (2010) nos afirma ainda que:

Apesar do jornalismo institucional ter um papel definido que é o de propagar as ações positivas de suas intuições, a construção textual exige do jornalista responsável por sua produção conhecimento de diversas linguagens, na medida em que a divulgação exigida precisa ter o modo de apresentação e a construção textual (a superestrutura) próprios de uma notícia, para evitar que o público-leitor entenda o texto como uma propaganda explícita deixando, assim, de ser um texto jornalístico. (SANTOS, 2010, p. 96)

Para o autor, a hibridização estará presente não na superestrutura do gênero notícia, mas nas escolhas argumentativas, na discursividade escolhida pelo profissional na elaboração do texto, como veremos adiante na análise do corpus.

\section{Revisão e revisor - novos paradigmas}

Definir o que seja revisão de texto não é tarefa fácil uma vez que há variados conceitos sobre o tema na literatura. $\mathrm{O}$ senso comum e mesmo o acadêmico entendem revisão como adequação do texto aos usos gramaticais tradicionalmente instituídos. Com o surgimento dos estudos da linguística, viu-se expandir esse leque de possibilidades cujos horizontes foram mais alargados ainda a partir dos estudos sobre gêneros textuais e suas implicações na análise discursiva. Entretanto, esses avanços, segundo Rocha (2012) e Macedo (2013), não se fazem presentes na formação e na prática dos profissionais de revisão de texto em geral.

Macedo (2013) traça um histórico sobre a atuação desse profissional lembrando que a princípio o revisor era alguém dotado de vasta cultura. Com a Revolução Industrial e consequente especialização das funções, essa realidade foi sendo mudada passando a ser o revisor um mero garantidor das normas ortográficas e gramaticais. A autora acrescenta que o advento das inovações tecnológicas, ocorridas no final do século XX, provocou mudanças significativas nas formas de comunicação o que fez surgirem vários gêneros textuais e com eles novos suportes e novos usuários que se utilizam tanto da linguagem verbal quanto da linguagem não verbal. Essas mudanças também possibilitaram a expansão da hibridização como forma de adequação da linguagem para atender às demandas comunicacionais. 


\section{CESPUC \\ 1 O SEMESTRE DE 2017 - N. 30}

A partir dessa contextualização, a autora alerta para a necessidade de o revisor de textos estar atento à necessidade de atualização de conhecimentos teóricos e práticos para além da gramática tradicional e da ortografia. É imprescindível que o profissional de revisão, hoje, saiba lidar com os novos mecanismos de comunicação para desempenhar a contento suas funções. O advento das TICs - Tecnologias de informação e comunicação, a profusão de novos gêneros textuais e a hibridização crescente para atender à demanda de comunicação dos grupos sociais exigem que esse profissional amplie seus horizontes abrangendo diversas áreas conforme nos alerta Macedo (2013):

No mundo-rápido-moderno, a palavra revisão se renova, entrelaçando-se não apenas com diagramação (uma vez que, ao revisor de hoje, demanda-se conhecimento de informática), mas também com conhecimentos linguísticos mais abrangentes, incluindo noções de gêneros textuais, de suportes, de variantes linguísticas, de imagens. (MACEDO, 2013, p. 33)

Essa abrangência não nega o valor da normatização e da prescrição, antes as une às demais áreas do conhecimento. Por sua vez, Costa; Rodrigues; Pena (2011) reforçam essa ideia ao afirmarem que:

Cabe ao revisor de textos, [...] propor alterações necessárias à adequação dos textos às condições de produção/recepção desses textos. E tais alterações compreendem desde as escolhas tipográficas e ortográficas, passando pelas gramaticais e lexicais, até as estilísticas e discursivas. (COSTA; RODRIGUES; PENA, 2011, p.72)

Podemos ver a importância da função desse profissional quando observamos a real dimensão de seu trabalho. O revisor deve propor alterações não só de natureza gramatical, mas também discursivas e de estilo visando o aprimoramento do texto. Estar atento a tantos detalhes requer não apenas empenho, mas formação e conhecimento em diversas áreas da linguagem. Para atender a essas demandas, o profissional precisa contar com materiais de pesquisa e com instituições que lhe ofereçam formação de qualidade, o que, segundo Costa; Rodrigues e Pena (2011), é mais uma dificuldade: "as universidades brasileiras apresentam escassez de cursos especializados em revisão de textos, restando poucas alternativas aos interessados, distribuídas em instituições como a PUC Minas, a UFMG e a Unicamp. " (COSTA; RODRIGUES; PENA, 2011, p.60).

Nessas afirmações acreditamos estar contida toda a relevância da mudança de paradigma que permeia a atuação e formação do profissional de revisão de textos. Podemos observar que é fundamental um novo posicionamento desse profissional diante do cenário atual a que está exposto e que ele deve ser protagonista das mudanças que envolvem sua função. Para isso, fazse necessário não apenas modificar a postura frente a seu próprio desempenho, mas lutar por espaços e reconhecimento no mercado de trabalho. 


\section{Coleta e análise dos dados}

Nossa análise se resumirá a uma publicação do DOM (Diário Oficial do Município) de Belo Horizonte, de 12 (doze) de dezembro de 2014 e de uma publicação do Informativo do Sindicato dos Trabalhadores em Educação da Rede Municipal de Belo Horizonte - SindRedeque circulou na mesma época. Os dois textos abordam o aniversário da cidade de Belo Horizonte e os motivos para se comemorar, ou não, essa data.

Destacaremos em cada texto recursos argumentativos que nos possibilitem verificar a hibridização ou intertextualidade genérica ali presentes. Para organização do material, o corpus será identificado como Texto A - Publicação do Diário Oficial do Município e Texto Bpublicação do Sindicato dos Trabalhadores em Educação da Rede Municipal

A partir dos recursos linguísticos destacados, podemos depreender que o texto A prima pelo positivismo em relação à instituição que representa. Esses elementos em conjunto nos dão a conhecer mais que o fato, pois destacam o mérito alcançado pela Instituição Pública. O texto B, por sua vez, estabelece um contraponto com o texto A criando uma paródia que desconstrói a argumentação da $\mathrm{PBH}$ e, em uma crítica clara e contundente, leva o cidadão a refletir sobre algumas afirmações feitas pela Prefeitura.

\section{Texto A}

\section{BH 117 anos - muitos motivos para comemorar ${ }^{1}$}

Cidade festeja aniversário inaugurando sua $100^{\mathrm{a}}$ Umei, com o reconhecimento de suas políticas públicas em diversas áreas e encerra o ano apontada como a melhor capital do país

Belo Horizonte completa hoje 117 anos. Fundada para ser a nova capital de Minas Gerais, já nasceu como símbolo da modernidade, por romper com o modelo urbanístico do final da década de 1890. Pouco mais de um século depois, consolidada como um dos mais importantes centros urbanos do país, sustenta o título de melhor capital brasileira, de acordo com o Índice das 100 Maiores e Melhores Cidades do Brasil (BCI 100), realizado pela consultoria Delta Economics \& Finance. Confira nesta e nas próximas páginas os motivos pelos quais $\mathrm{BH}$ tem muito a comemorar.

\section{Centésima Umei é inaugurada na Pampulha}

Na véspera de seu aniversário, Belo Horizonte ganhou sua $100^{a}$ Unidade Municipal de Educação Infantil (Umei). Ontem, a Prefeitura inaugurou a Umei Santa Branca (Rua Campista, 70, bairro Santa Branca, Pampulha). Vinculada pedagógica e administrativamente à Escola Municipal Amílcar Martins, a Umei tem capacidade para atender 440 alunos e iniciou suas atividades em julho. Hoje, 210 crianças frequentam a nova unidade.

O prefeito Marcio Lacerda e a secretária municipal de Educação, Sueli Baliza, participaram da solenidade de inauguração. Para Marcio, as Umeis beneficiam os moradores com o que é mais importante para formação de cidadãos, a educação de qualidade nos primeiros anos de vida. "Assim, podemos construir uma sociedade melhor, com promoção da democracia e responsabilidade social", destacou.

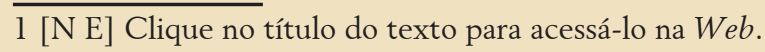


De acordo com Sueli Baliza, a educação de qualidade é primordial para o desenvolvimento dos alunos e continuará sendo o foco principal em 2015. "O trabalho em prol da educação continuará sendo executado de forma sistemática. Serão implantados o Plano de Segurança Escolar, o Observatório do Clima Escolar e diversas outras ações no próximo ano", disse.

As crianças que frequentam a Umei Santa Branca têm à disposição um prédio de dois pavimentos, com cozinha, refeitório, despensa fria, instalações sanitárias adaptadas por idade e turma, pátio coberto, duas salas de aula para crianças de 1 e 2 anos, sala multiuso, biblioteca, fraldário, berçário, sala de atividades, sala de coordenação, secretaria, depósito e elevador, além de oito salas de aula para crianças de 3 a 5 anos, sala de reuniões e instalações sanitárias adaptadas. A unidade possui ainda uma área externa com estacionamento, horta, jardins, parquinho, auditório, pátio e estruturas para a colocação de resíduos e alocação de botijões de gás.

A Umei Santa Branca foi construída por meio de Parceria Público-Privada (PPP), com investimento de $\mathrm{R} \$ 3,7$ milhões. Desse valor, $\mathrm{R} \$ 1,3$ milhão foi repassado pelo Fundo Nacional de Desenvolvimento da Educação (FNDE).

\section{Ampliação}

Com o compromisso de ampliar as vagas na educação infantil, a Prefeitura construiu, nos últimos seis anos, 60 Umeis, sendo 26 em 2014. Assim, encerra o ano com 100 Umeis, 13 escolas municipais de educação infantil e outras 19 escolas municipais de ensino fundamental com turmas de educação infantil. Conta ainda com 197 instituições parceiras, que recebem repasses da Prefeitura para o atendimento de crianças de até 5 anos. Em 2014, a educação infantil do município capacitou-se para atender 52 mil crianças. A Prefeitura tem por meta dotar Belo Horizonte de 153 Umeis até 2016, preparando a cidade para atender as exigências da lei de Diretrizes de Base da Educação, que determina a universalização do atendimento escolar a crianças de 4 e 5 anos.

A PPP da Educação é uma iniciativa pioneira no país, que possibilita a construção de novas unidades com mais economia e agilidade. Com a PPP, a construção das Umeis e a operação de serviços não pedagógicos, como manutenção das instalações elétricas e hidráulicas, segurança e limpeza, além dos cuidados com a sustentabilidade ambiental e o mobiliário ficam sob a responsabilidade da empresa parceira pelo período de 20 anos. Com isso, os gestores e demais profissionais da educação podem se dedicar exclusivamente ao projeto pedagógico e ao relacionamento com as famílias. (DIÁRIO OFICIAL DO MUNICIPIO DE BELO HORIZONTE, 2014, PRIMEIRA PÁGINA)

Já na Manchete, a expressão 'muitos motivos para comemorar' chama a atenção por despertar no leitor o interesse por quais seriam os motivos de comemoração, levando-o à leitura da reportagem. No 'olho' em: a 'cidade festeja aniversário [...] com reconhecimento de suas políticas públicas em diversas áreas, ' o tom é de enaltecimento das ações realizadas pela instituição Prefeitura e acrescenta: 'apontada como a melhor capital do país,' indicando a visibilidade que a administração conseguiu alcançar em âmbito nacional. No primeiro parágrafo a expressão: 'já nasceu como símbolo da modernidade' é um elogio rasgado. Mesmo que, a princípio, não seja direcionado para a administração atual, reforça a pretensa superioridade da Instituição, o que é reforçado nos trechos: 'consolidada como um dos mais importantes centros urbanos' e 'sustenta o título de melhor capital brasileira'. Neste último, a escolha do verbo sustentar indica a capacidade e a força da Instituição. Na expressão: 'em seu aniversário Belo Horizonte ganhou sua $100^{\mathrm{a}}$ UMEI (Unidade de Educação Infantil)’ o leitor é levado 


\section{CESPUC

a aderir à ideia de que a UMEI é um presente recebido pela cidade e não uma etapa do cumprimento de uma obrigação política para com o cidadão. Essa ideia de benesse é reforçada pelas expressões 'beneficiam os moradores' e 'as crianças têm à disposição'. A fala da secretária de educação endossa a mesma postura quando afirma que: 'o trabalho em prol da educação continuará sendo o foco principal em 2015’. O parágrafo do intertítulo - Ampliação - inicia-se com a afirmação: 'com o compromisso de ampliar vagas na educação infantil, a Prefeitura construiu [...] 60 Umeis [...]' e acrescenta: 'a educação infantil do município capacitou-se para atender 52 mil crianças'. Essas informações alertam para a atenção com que a Instituição trata as questões de sua competência. Por fim afirma que: 'a PPP da Educação é uma iniciativa pioneira no país' e que possibilita a construção [...] com mais economia e agilidade. Essa argumentação busca convencer o leitor-cidadão do acerto da medida frente às demandas de novas Umeis para atender as exigências da Lei de Diretrizes e Bases da Educação que determina que todas as crianças de 4 e 5 anos tenham atendimento escolar obrigatório até o final do corrente ano de 2014. Segue-se a isso o fato de que a PPP (Parceria Público Privada) é uma iniciativa controversa que vem sofrendo bastantes críticas dos movimentos sociais, pois é um passo importante no processo de privatização da educação no município.

Podemos perceber que há, ao longo do texto, uma clara intenção de se promover a Prefeitura o que caracteriza propaganda implícita, corroborando a afirmação de que o hibridismo não se dá na estrutura textual, mas na argumentação, na discursividade textual.

\section{Texto B}

\section{PARABÉNS BH! VOCÊ TEM O QUE COMEMORAR?²}

Informativo dos trabalhadores em educação da rede publica municipal de $\mathrm{BH}$

Nesta sexta-feira, 12 de dezembro de 2014, Belo Horizonte completa 117 anos. Será que temos motivos para comemorar? Nos últimos seis anos convivemos com a precariedade de atendimento na Saúde, falta de vagas nas escolas para as crianças, jovens e adultos, sucateamento dos serviços de limpeza urbana, ausência de uma política de segurança pública que priorize a vida e os direitos sociais, além do completo descaso com o dinheiro público.

Em relação aos servidores públicos municipais que, além de cidadãos, trabalham pela cidade e lutam pela qualidade dos serviços públicos oferecidos à população, há o que comemorar? Qualquer belorizontino que utiliza os serviços públicos oferecidos pelo Município será capaz de responder esta pergunta.

Estes trabalhadores convivem diariamente com a constante precarização de suas condições de trabalho e retirada arbitrária de direitos trabalhistas históricos conquistados pela categoria. Excesso de trabalho falta de valorização e condições minimamente dignas para execução do serviço são, infelizmente, parte da rotina dos trabalhadores da Prefeitura de Belo Horizonte $(\mathrm{PBH})$.

CONFIRA ALGUNS DOS "PRESENTES” DE LACERDA PARA OS SERVIDORES

2 [N E] Clique no título do texto para acessá-lo na $W e b$. 


\section{CESPUC}

\section{MUNICIPAIS:}

\section{SAÚDE PRECARIZADA}

Nenhuma das unidades de Saúde prometidas pelo Prefeito Márcio Lacerda, durante sua primeira campanha eleitoral, ainda em 2008, foi entregue à população. No Plano de Governo do então candidato à Prefeitura, Márcio Lacerda, constavam como "prioridades" a construção do Hospital Metropolitano do Barreiro, de oito Unidades de Pronto Atendimento (UPAs) e as 81 Unidades Básicas de Saúde. Estamos no final de 2014 e nenhuma destas obras foi entregue à população de Belo Horizonte.

\section{NA EDUCAÇÃO, UM PREFEITO SEM PRESSA...}

Lacerda foi o único prefeito dentre todas as capitais do país a alterar o calendário escolar por causa da Copa do Mundo e, ainda por cima, sem nenhuma consulta à população. Ao invés de negociar, foi aos jornais dizer: "Eu não tenho pressa em negociar" e "Não me preocupo com as manifestações. Nós temos férias escolares no período da Copa, portanto, a educação não é um problema". Ou seja, a falta de vagas nas Unidades Municipais de Educação Infantil (UMEIs), o aumento significativo da violência nas Escolas, além de todos os problemas estruturais da Educação Pública no Município não são considerados problemas para o prefeito, nem antes, nem durante e, muito menos, depois da Copa.

\section{ATRASO NO PAGAMENTO DOS SERVIDORES}

Em setembro de 2014 a PBH divulgou um novo cronograma de pagamento para o funcionalismo municipal, como sempre apresentado de forma unilateral; sem nenhum diálogo com os trabalhadores. Após anos recebendo no $5^{\circ}$ dia útil de cada mês, os servidores municipais foram obrigados a readaptar sua vida financeira recebendo seus salários, já defasados, com atrasos que chegam a quase duas semanas em alguns meses.

Infelizmente, os empresários e especuladores financeiros que tomaram de assalto a Prefeitura da capital não precisam honrar seus compromissos financeiros ao final de cada mês e, por isso, são incapazes de entender as necessidades daqueles que trabalham de verdade para pagar suas contas.

\section{AUMENTO DA VIOLÊNCIA CONTRA OS SERVIDORES}

A violência contra os servidores municipais aumentou significativamente em 2014. Não existem registros oficiais, no entanto denúncias de agressão chegam aos Sindicatos constantemente e ganham destaque na imprensa. As condições precárias dos serviços públicos prestados à população favorecem a exposição do servidor à violência que tem sido, infelizmente, parte da rotina dos trabalhadores.

\section{FALTA DE ESTRUTURA PARA ATENDER A POPULAÇÃO}

O prefeito fez e refez obras na cidade e várias foram as denúncias de superfaturamento, mas os volumosos gastos não representam qualidade e isso é facilmente perceptível nas condições precárias e falta de estrutura em equipamentos do município como Centros de 


\section{CESPUC}

Saúde, Escolas/UMEIs, dentre outros. Esta precariedade teve uma maior visibilidade após a queda de um dos novos viadutos do Complexo do BRT/MOVE que provocou a morte de duas pessoas.

\section{ALTERAÇÕES NA AVALIAÇÃO DE DESEMPENHO}

Como se não bastasse as precárias condições de trabalho, a falta de respeito e valorização por parte da $\mathrm{PBH}$ tanto com a população quanto com o funcionalismo municipal, a Prefeitura deseja agora retirar direitos trabalhistas históricos conquistados pela categoria, por meio de uma perversa proposta de alteração das regras de Avaliação de Desempenho dos servidores municipais.

Entre as mudanças propostas, estão o término da Auto avaliação e Avaliação dos Pares (colegas de trabalho), restringindo todo o poder de avaliação dos trabalhadores apenas aos gerentes; aumento do índice mínimo de aprovação de $70 \%$ para $90 \%$ e o fim do atual processo de progressão por escolaridade mediante apresentação de títulos, criando uma nova progressão vertical e restritiva na qual apenas um percentual de servidores, estabelecido pelo governo, poderá progredir verticalmente por meio de seleção interna.

Na última quarta-feira (10/12), os trabalhadores da PBH ocuparam e lotaram as galerias do Plenário Amynthas de Barros, na Câmara Municipal de Belo Horizonte (CMBH), durante Audiência Pública que discutiu as mudanças na Avaliação de Desempenho propostas pela Prefeitura e deram seu recado:

\section{NÃO ACEITAREMOS MAIS AS IMPOSIÇÕES E ARBITRARIEDADES DESTE GOVERNO!}

(Sindicato dos Trabalhadores em Educação da Rede Municipal de Belo Horizonte informativo -dez. 2014.)

O texto inicia-se parabenizando a cidade e questionando a existência de motivos a comemorar numa clara referência ao texto da $\mathrm{PBH}$ (Prefeitura de Belo Horizonte) que afirma haver 'muitos motivos' para isso. A pergunta: 'Você tem o que comemorar?' pode ser interpretada como dirigida a cada cidadão -'você'- ou à própria cidade. No primeiro parágrafo esse questionamento é reforçado usando-se a primeira pessoa do plural - 'Será que temos motivos para comemorar?' A resposta vem em seguida através de informações sobre a 'precariedade de atendimento' em diversos setores do Serviço Público Municipal, numa evidente menção à falta de motivos que a população teria para a pretensa comemoração. Surge outra interrogação. Dessa vez endereçada ao Servidor Público. E a afirmação categórica de que o cidadão belorizontino sabe a resposta, pois vive sob o efeito da precariedade dos serviços prestados como já mencionado anteriormente. A seguir, enumera algumas dificuldades que o Servidor Municipal enfrenta em seu cotidiano como trabalhador da $\mathrm{PBH}$ para desempenhar suas funções e oferecer ao público um serviço de qualidade.

O intertítulo, 'Confira alguns dos “presentes” de Lacerda para os Servidores Municipais', 
ironicamente, chama a atenção para o que o Prefeito tem oferecido aos servidores e aos cidadãos e enumera: 'Saúde precarizada; desinteresse em resolver os problemas da Educação; a falta de 'estrutura dos aparelhos públicos municipais' para atender ao cidadão; o que provoca um aumento da violência contra os servidores; atrasos no pagamento dos funcionários e mudanças na 'avaliação de desempenho' que retiram do trabalhador a possibilidade de progressão na carreira. Ao finalizar essa lista deixa claro que o servidor não aceitará as 'imposições e arbitrariedades' do governo municipal.

Assim como no texto $\mathrm{A}$ a estrutura textual pertence ao gênero notícia. A ironia não deixa dúvidas de que a intenção é parodiar o texto Institucional. Entretanto, as escolhas argumentativas apontam para o gênero carta aberta.

Observa-se, mais uma vez, que o fenômeno da hibridização se dá não na estrutura textual, mas na argumentação, na discursividade.

Numa análise comparativa, em relação ao uso da linguagem, observa-se no texto A a predominância da linguagem formal. A Instituição se dirige a um público leitor bastante específico, acostumado a acompanhar o Diário Oficial do Município - DOM - em busca de informações sobre legislações e ações executivas. O cuidado com a linguagem, portanto, é fundamental para assegurar a imagem de Instituição oficial e o comprometimento com o seu público. No texto B, temos uma mescla de linguagem formal e linguagem informal. O Sindicato dos trabalhadores em Educação da Rede Municipal de Belo Horizonte tem um público leitor bastante heterogêneo tanto em relação ao nível socioeconômico, como em relação à escolaridade. O uso da linguagem informal facilita a comunicação e aproxima a Instituição de seu público. A preocupação com o público leitor, em ambos os textos, é que dá o tom do discurso e que determina a escolha da linguagem a ser utilizada.

Um revisor atento deve perceber a intenção das escolhas linguageiras no texto e propor apenas intervenções que não comprometam o objetivo traçado. Dessa forma, tendo em vista a adequação da linguagem informal em alguns momentos do texto $B$, as marcas de oralidade não devem ser excluídas. Observemos algumas ocorrências: 1- 'ainda em 2008' em lugar de 'no ano de 2008'; 2- 'ainda por cima' - totalmente desnecessário no contexto; 3- 'Foi aos jornais dizer' em lugar de 'declarou aos jornais'. 4- '[...] teve uma maior visibilidade [...] em lugar de 'teve maior visibilidade'. Da mesma forma, a redundância em: 'de forma unilateral, sem nenhum diálogo com os professores'. Também é justificável o emprego do verbo 'existir' em substituição a 'haver'.1 - 'Não existem registros' em lugar de 'Não há registros'.

Há outros aspectos, no entanto, que devem ser alterados, pois não dizem respeito à informalidade na comunicação, mas à inadequação gramatical. 1- Conjugação verbal 'Qualquer belorizontino que utiliza os serviços [...]'. 'Utiliza' - presente do indicativo, em lugar de 'utilize' - futuro do subjuntivo. 2- Marcador de temporalidade -'[...] retirar direitos trabalhistas históricos conquistados pela categoria'; em lugar de ' retirar direitos trabalhistas historicamente conquistados' . 3 - Simetria no uso de preposições: A - '[...] convivem diariamente com a constante precarização de suas condições de trabalho e retirada arbitrária de direitos [...] Em lugar de "[...] convivem diariamente com a constante precarização de suas condições 
de trabalho e com a retirada arbitrária de direitos [...] '. B -'Excesso de trabalho, falta de valorização e condições minimamente dignas. ' Em lugar de 'falta de valorização e de condições [...]', ou ainda, 'desvalorização' e 'falta de condições [...]'. C - '[...] é facilmente perceptível nas condições precárias e falta de estrutura em [...]'. Em lugar de 'é facilmente perceptível nas condições precárias e na falta de estrutura em [...]. 4- Emprego dos pronomes demonstrativos esta/essa; deste/desse. A - '[...] nenhuma destas obras [...]" em lugar de "nenhuma dessas obras'. B- 'Esta precariedade[...] em lugar de 'essa precariedade'. C- '[...] deste Governo' em lugar de desse Governo. 5 - Elipse de termo da oração. 'Lacerda foi o único prefeito dentre todas as capitais do país' em lugar de 'foi o único prefeito dentre os de todas as capitais [...]'. 6 - Adequação vocabular. '[...], mas os volumosos gastos não representam qualidade [...] em lugar de 'vultosos gastos'. 7 - Concordância verbal. 'Como se não bastasse as precárias condições de trabalho [...] em lugar de 'Como se não bastassem as precárias condições de trabalho'.

\section{Conclusão}

Embora o gênero artigo não nos permita aprofundar a discussão, procuramos provocar algumas reflexões sobre o trabalho do revisor de textos a partir da teoria dos gêneros e do hibridismo textual como elementos indispensáveis para o desempenho das funções desse profissional incentivando-o a buscar novos conhecimentos a cerca do tema. O corpus escolhido para análise teve como objetivo exemplificar o fenômeno da hibridização comprovando que o mesmo se dá nas escolhas discursivas e ressaltar a importância do conhecimento dos gêneros para a percepção dessas nuances que permeiam cada texto, além do papel do revisor, conforme nos afirma Rocha (2012) na conclusão de sua tese:

O revisor de texto deve ter uma visão crítica diante do gênero textual a ser revisado e levar em consideração, não só os aspectos verbais escritos, e, ainda, outros recursos semióticos (não verbais) também responsáveis pela construção de sentido e de efeitos discursivos em contextos sociais. (ROCHA, 2012, p. 231)

Temos clareza da extensão do tema e das inúmeras questões que não foram abordadas, mas acreditamos possa servir de incentivo para quantos o leiam procurar aprimorar seus conhecimentos, especialmente se estiverem inseridos no contexto profissional da revisão de textos

\section{Referências}

AZEVEDO FILHO, Carlos Alberto Farias de. Hibridismo e ruptura de gêneros em João Antonio. Assis: Tese (doutorado), UNESP/FCLA, 2008. Disponível em: http://www.cedap. assis.unesp.br/acervo_joao_antonio/Doutorado/CARLOS\%20ALBERTO\%20FARIAS\%20 DE\%20AZEVEDO\%20FILHO.pdf. Acesso em: dez. 2014

BAKHTIN, Mikhail. Os gêneros do discurso. In: BAKHTIN, Mikhail. Estética da criação 


\section{CESPUC \\ 1 O SEMESTRE DE $2017-$ N. 30}

verbal. 4 ed. Trad. de Paulo Bezerra 4.ed. São Paulo: Martins Fontes, 2003. p. 260-306.

COSTA, Roger Vinícius da Silva; RODRIGUES, Daniella Lopes Dias Ignácio; PENA, Daniela Paula Alves. Dificuldades no trabalho do revisor de textos: possíveis contribuições da Linguística. Revista Philologus, Rio de Janeiro, suplemento, ano 17, n. 51, p. 53-74, set/ dez. 2011 . Disponível em: http://www.filologia.org.br/revista/51supl/05.pdf. Acesso em: dez. 2014

DIÁRIO OFICIAL DO MUNICÍCPIO DE BELO HORIZONTE. Primeira página, 12 de dezembro de 2014. Disponível em: http://portal6.pbh.gov.br/dom/iniciaEdicao.do?method= DetalheArtigo\&pk=1134015. Acesso em: fev. 2014

FIORIN, José Luiz. Introdução ao pensamento de Bakhtin. São Paulo: Ática, 2008

MACEDO, Denise Silva. As contribuições da Análise de Discurso Crítica e da Multimodalidade à Revisão Textual. Brasília: Dissertação, Unb/LIP, 2013. Disponível em: http://repositorio. unb.br/bitstream/10482/14150/1/2013_DeniseSilvaMacedo.pdf. Acesso em: dez. 2014

MARCUSCHI, Luiz Antonio. Gêneros textuais: definição e funcionalidade. In: Dionísio, Angela Paiva; Machado, Anna Raquel, Bezerra, Maria Auxiliadora, (Org.) Gêneros Textuais \& Ensino. 5.ed. Rio de Janeiro: Lucerna, 2007. P.19-36.

PAGANO, Adriana Silvina. Gêneros híbridos. In: Magalhães, Célia Maria (Org) et all. Reflexões sobre Análise Crítica do Discurso. Belo Horizonte: Faculdade de Letras, UFMG, 2001. Cap. 3, p. 83-119.

ROCHA, Harison. Um Novo Paradigma de Revisão de Texto: Discurso, Gênero e Multimodalidade. Brasília: Tese (doutorado), Unb/LIP, 2012. Disponível em: http://repositorio. unb.br/handle/10482/11956 Acesso em: dez. 2014.

SANTOS, Josemar. Jornalismo institucional: metáforas conceituais e recursos argumentativos presentes no discurso jornalístico. Santa Cruz do Sul: Dissertação (Mestrado), UNISC, 2010. Disponível em: http://livros01.livrosgratis.com.br/cp150253.pdf. Acesso em dez. 2014.

SINDICATO DOS TRABALHADORES EM EDUCAÇÃO DA REDE MUNICIPAL DE BELO HORIZONTE. Informativo. Dez. 2014. Disponível em: http://www.redebh.com.br/ wa_files/VERS_C3_83O_20FINAL_20ENCARTE-12-12-14.pdf 